\title{
Implementation of greywater heat recovery system in hospitals
}

\author{
Edyta Dudkiewicz ${ }^{1}$, Agnieszka Ludwińska ${ }^{1, *}$, and Krzysztof Rajski ${ }^{1}$ \\ ${ }^{1}$ Department of Air Conditioning, Heating, Gas Engineering and Air Protection, \\ Faculty of Environmental Engineering, Wroclaw University of Science and Technology, \\ Wybrzeże Wyspiańskiego 25, 50-373 Wroclaw, Poland
}

\begin{abstract}
The constant demand for domestic hot water (DHW) creates great opportunity for drain water heat recovery (DWHR) systems in hospitals, so there is an enormous potential to reduce energy consumption in accordance to the EU environmental policy. This paper aims to assess the energy saving from greywater in hospitals. The energy analysis considered the type, constructions, efficiency of the proposed four types of heat exchangers (HEX). The measured data from two Polish hospitals was elaborated and calculated for two supply cold water temperatures: constant and variable. Results ensure that implementation of HEX type GFX allows to save up $30 \%$ of the energy demand.
\end{abstract}

\section{Introduction}

At the end of year 2016 in Poland worked 957 public hospitals with 186.6 thousands of beds and 194 one-days hospitals with 1.2 thousands of beds. In references to Polish Central Statistic Office (GUS) data for 100 thousands residents fall 2.5 bed and for one bed falls average 206 residents [1]. Hospitals are intensive consumers of heat energy, reaches $550 \mathrm{kWh} / \mathrm{m}^{2}$ year [1-3]. Also water consumption in healthcare buildings is substantial, particularly hot water as a result of frequent activities related to patients hygiene, kitchen service and cleaning. Hot water demand could reach to 240 l/bed. Simultaneously hospitals administer great potential to apply measures of energy saving due to 24-hour operation (lighting, heating, air condition, electricity and water consumption).

The use of greywater is one of the alternative energy source in a hospitals due to the typical constant demand for domestic hot water (DHW) throughout the year. The most popular methods of recovering waste heat from drain water are based on heat exchangers (HEX). Due to the great waste heat energy hospitals can be also integrated to low temperature district heating using heat pumps [4]. This work aims to estimate the possibility of reducing of energy to hot water preparation in Polish hospitals as a result of implementation heat recovery system installing on greywater system, draining sewage from wash basins and showers. The study is based on produced in [2] actual data for two hospitals located in Poland.

\footnotetext{
*Corresponding author: agnieszka.ludwinska@pwr.edu.pl
} 


\section{Water consumption in hospitals}

Substantial amount of energy is consume for hot water preparation in hospitals $[2,3]$. The demand for DHW is primarily due to use of showers and wash basins by patients, kitchen and cleaning [3]. The average daily DHW consumption per bed in hospitals varies from 80 to $130 \mathrm{l} / \mathrm{bed}$ in Europe and from 100 to $150 \mathrm{l} / \mathrm{bed}$ in the USA [2, 3]. The annual consumption of DHW and cold water can be calculate by the formulas presented in [5] considering $\mathrm{B}$ as the number of hospitals beds. In Poland, in reference to [6], water consumption depends on type and size of hospital, kind of unites and varies between 50 to 240 1/bed. Table 1 presents range of hot water demands about temperature $60^{\circ} \mathrm{C}$ in reference to recommended Polish publications [6-9]. It shows also actual values measured in two Polish hospitals with about 700 beds [2]. The average daily DHW consumption reaches 111 l/bed in hospital A with 715 beds and 124 1/bed in hospital B with 690 beds and calculated thermal energy demand is $6390 \mathrm{Wh} /$ bed and $7290 \mathrm{Wh} /$ bed respectively (see Table 1). The value $325 \mathrm{l} / \mathrm{bed}$ of hot water in hospital, mentioned in [2], should be only use in situation when water meter is not installed in building.

Table 1. Demand of hot water and energy for water preheated in various type of hospitals.

\begin{tabular}{|c|c|c|c|}
\hline Hospital & $\begin{array}{c}\text { DHW demands about } \\
\text { temp. } \mathbf{~ 6 0}^{\circ} \mathbf{C}, \\
\text { //bed }\end{array}$ & $\begin{array}{c}\text { Thermal energy } \\
\text { demand, } \\
\text { Wh/bed }\end{array}$ & Ref. \\
\hline $\begin{array}{c}\text { Public many wards to 500 beds } \\
\text { (without kitchen and laundry) }\end{array}$ & 140 & - & {$[6]$} \\
\hline $\begin{array}{c}\text { Public many wards to 500 beds } \\
\text { (with kitchen and laundry) }\end{array}$ & 180 & - & {$[6]$} \\
\hline For children with kitchen and laundry & 195 & - & {$[6]$} \\
\hline $\begin{array}{c}\text { Gynaecological-obstetric with kitchen } \\
\text { and laundry }\end{array}$ & 240 & - & {$[6]$} \\
\hline $\begin{array}{c}\text { Public many wards over 500 beds } \\
\text { (without kitchen and laundry) }\end{array}$ & 180 & - & {$[6]$} \\
\hline Public & $100-300$ & 2910 & {$[7]$} \\
\hline With normal medical equipment & 50 & 5235 & {$[8]$} \\
\hline With mediocre medical equipment & 70 & - & {$[8]$} \\
\hline With rich medical equipment & 90 & 6390 & {$[2]$} \\
\hline Public & $150-180$ & 7290 & {$[2]$} \\
\hline $\begin{array}{c}\text { Hospital A - University Hospital in } \\
\text { Bydgoszcz with 715 hospital beds }\end{array}$ & 111 & & \\
\hline $\begin{array}{c}\text { Hospital B - The 690 beds Provincial } \\
\text { Hospital in Włocławek, Poland }\end{array}$ & 124 & - & \\
\hline
\end{tabular}

For energy recovery system is important hot water consumption profile. In hospitals demand of water is fairly equal throughout the all year $[2,5]$. It is noticed fluctuations during the week. On Saturdays and Sundays the average DHW consumption is lower than the overall average. It is also observed the daily time period with greater consumption mostly between 10.00 am to $2.00 \mathrm{pm}$. Hourly hot water consumption irregularity coefficient for healthcare buildings should be assume to 2.5 [6]. That hot water consumption pattern creates great benefit for implementation recovery and alternative energy systems $[2,3,10,11]$. Heat recovery is a powerful way of saving energy in hospitals particularly with using various control techniques.

In according to the European Standards in systems of waste water are distinguished two types of sewage: grey sewage (greywater) and black sewage. The term "black sewage" is defined as cold waste water discharged from toilet bowls and urinals, at the temperature of 
about $10^{\circ} \mathrm{C}$, whereas the "greywater" is the outflows from bathtubs, showers, washbasins, washing machines or dishwashers.

The core of DWHR system (Fig. 1) is the heat exchanger, in which the greywater (with temp. $T_{2}$ ) from drain water sources flows and preheats cold water to temperature $T_{1}$.

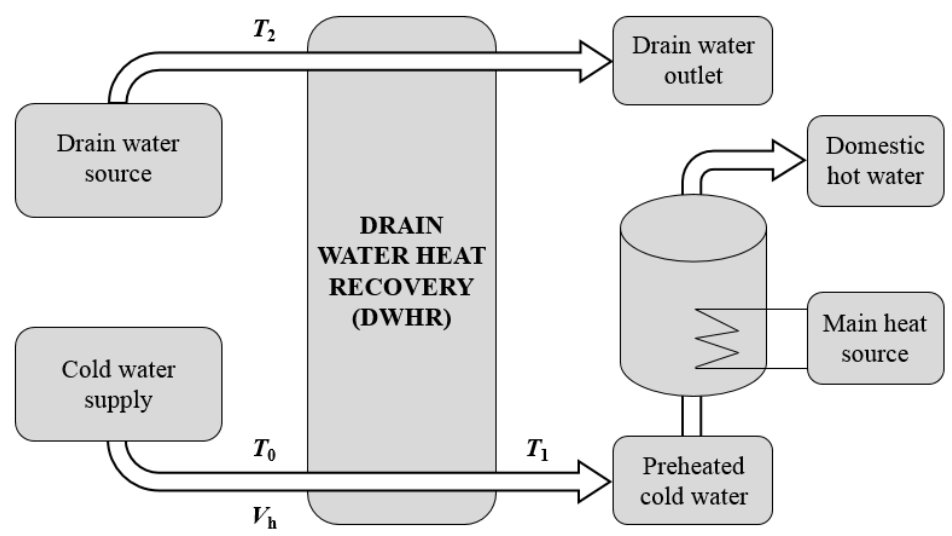

Fig. 1. The working principle of drain water heat recovery system in hospitals.

The efficiency $\varepsilon$ of the greywater heat recovery system is defined as follows [10]:

$$
\varepsilon=\left(T_{1}-T_{0}\right) /\left(T_{2}-T_{0}\right)
$$

where $T_{0}$ is the temperature of the inlet cold water, $T_{1}$ is the preheated warm water that passes through the exchanger, $T_{2}$ is the drained wastewater temperature.

Heat consumptions for preparing DHW without heat recovery $\left(Q_{0}\right)$ and the heat consumption with heat exchanger $\left(Q_{1}\right)$ are determined by the following formulas:

$$
\begin{aligned}
& Q_{0}=V_{\mathrm{h}} / 3.6 \cdot \rho \cdot c_{\mathrm{p}} \cdot\left(T_{2}-T_{0}\right), \mathrm{kWh} / \mathrm{bed} \\
& Q_{1}=V_{\mathrm{h}} / 3.6 \cdot \rho \cdot c_{\mathrm{p}} \cdot\left(T_{2}-T_{1}\right), \mathrm{kWh} / \mathrm{bed}
\end{aligned}
$$

where $V_{\mathrm{h}}$ in $1 / \mathrm{h} \cdot$ bed is the hourly hot-water mean flow rate, $c_{p}$ in $\mathrm{kJ} / \mathrm{kg}$ and $\rho$ in $\mathrm{kg} / \mathrm{m}^{3}$.

\section{Heat exchangers used in DWHR systems - overview}

The DWHR systems with HEX are widely used in residential, commercial and industrial buildings $[10,12]$. Particularly noteworthy is the heat recovery from greywater, which is characterized by significant high temperature, so it can be used to DHW preheating in buildings. The application of the DWHR system is suitable for energy reasons (minimizes fossil fuel consumption energy consumption for heating DHW), ecologically (reduces the emission of pollution and greenhouse gases into the atmosphere) and economically (allows long-term savings with acceptable investment costs).

Drain water temperature varies between 35 and $39^{\circ} \mathrm{C}$ for the different DHW end-uses in bathrooms. The temperature can also be determined by knowing the DHW temperature used for bathing or hand washing and assuming a heat loss coefficient $(\mathrm{x})$ on the pipes from the bathroom to DWHR system equal $\mathrm{x}=0.95$ [11]. The temperature of DHW for various end-use applications is respectively: for bath filling and showering: $40^{\circ} \mathrm{C}$, for hand washing: $35^{\circ} \mathrm{C}[13]$.

Greywater as a heat source depends on the amount of DHW used in buildings. Therefore, it is particularly appropriate to recover energy from these wastewater in 
buildings where they are available in large quantities. Such buildings include: hospitals, hotels, laundries, swimming pools, multi-family buildings, spas and industrial plants.

The DWHR system can be implemented in different locations in the wastewater system. In the building can be distinguished the DWHR system location at component level, i.e. household appliances using DHW, or at property level, i.e. heat is recovered from collected greywater from the property and recycled for preheating tap water [10].

Heat exchangers are efficient solution without the need for any external energy source and having minimal maintenance requirements. Their use makes possible to recover from $40-80 \%$ of the energy content of the greywater. These values are dependent on the heat exchanger design. For the application of DWHR system, it is important that the HEX are double walled to avoid any leakages to the incoming clean drink water [12]. For this reason, it is not recommended using typical for systems of DHW preparation, JAD type shell and tube heat exchangers.

Four main types of HEX can be distinguished to DWHR system at the building level [12]. These are: vertical shell and tube HEX type GFX (Gravity-Film Exchangers) and pipe-in-pipe, shell and tube tank HEX and horizontal HEX. An additional possibility of energy recovery from wastewater can be the use of heat pipe based heat exchangers [14].

\subsection{Shell and tube Gravity-Film Exchangers (HEX type GFX )}

HEX type GFX are installed on drain pipes below shower. They are made with copper, aluminum or even plastic. These DWHR systems consists of a large diameter central pipe and a smaller diameter pipes which are looped around the drain pipe. Grey water due to gravity flows down inside a vertical central pipe. As a result of the surface tension, it clings to the circumference forming a thin film on this pipe. This allows good heat transfer. Cold tap water flows in pipes looped around the circumference.

\subsection{Shell and tube pipe-in-pipe HEX}

Pipe-in-pipe heat exchangers are the cheapest and the simplest solutions among all exchangers in DWHR systems. They are made with two concentric pipes - grey water flows inner drain pipe and the cold water flows in a thin area between the drain pipe and a pipe with a slightly larger diameter fixed around it. The principle of operation is similar to that of GFX type exchangers. Very often, the inner pipe is covered with a coating to prevent possible mixing of tap water and grey water.

These two aforementioned systems are primarily focused on the heat recovery of greywater from a single bathroom. There are also solutions for energy recovery from more bathrooms. They are created by the parallel connection of several (up to ten) pipes into units and installed close to DHW preparation system, so can be applied with good results in hospitals. Depending on the height of such HEX and the flow of greywater, it is possible to recover energy within $20-70 \%$.

Vertical systems are available in various heights up to about two meters. Due to the height they are often installed in the basement. The vertical units are the most effective and the most popular from all types of DWHR systems. This type is produced by many manufacturers both in Europe, as well as in USA and Canada [10]. 


\subsection{Shell and tube tank HEX}

Shell and tube tank HEX is consists of a tank and a coil placed within. Greywater from showers is stored in the tank, and the cold tap water flows through the coil. This solution allows energy recovery from greywater within $35-43 \%$ depending on the greywater flow. Due to high capacity of water these HEX seems to be applicable in hospitals.

\subsection{Horizontal HEX}

Horizontal HEX in DWHR systems are designed primarily for installation near or directly under the showers. In this version they are adapted to greywater heat recovery from single bathrooms (showers). However, there are also solutions adapted for main drain lines from the building. They are made with plastic (first generation) or copper (new generation).

There is a possibility to embed horizontal HEX within main pipeline or place it on the bottom section of main pipeline. In this second case the heat exchanger consists only of pipes in which tap water flows and can be installed on an existing sewage pipe for greywater. The efficiency of horizontal HEX is lower than for vertical installed exchangers [12]. Their application allows to recover energy from grey water at the level $40 \%$ and seems to be possible implemented in hospitals.

Table 2 presents manufacturer data for four analysed types of heat exchangers used in DWHR systems.

Table 2. Type of heat exchangers used in analysed DWHR systems.

\begin{tabular}{|c|c|c|c|c|}
\hline System & Manufacturer & Model & $\varepsilon, \%$ & Comments \\
\hline & \multicolumn{4}{|c|}{ Shell and tube heat exchanger - type GFX } \\
\hline \multirow[t]{2}{*}{ I } & $\begin{array}{l}\text { Eco Innovations } \\
\text { Technology Inc. }\end{array}$ & $\begin{array}{l}\text { ThermoDrain } 4 " \\
\text { Series - TD472B }\end{array}$ & 58.4 & $\begin{array}{l}\text { Obtained at the flow of } \\
9.5 \mathrm{l} / \mathrm{min} \text {, equal media } \\
\text { flow }\end{array}$ \\
\hline & \multicolumn{4}{|c|}{ Shell and tube heat exchanger - pipe-in-pipe } \\
\hline \multirow[t]{2}{*}{ II } & Q-Blue & $\begin{array}{c}\text { Showersave } \\
\text { Multivert10 } \times \mathrm{QB} 1-21\end{array}$ & $30.0-50.0$ & $\begin{array}{c}\text { Efficiency for HEX } \\
\text { acc. manufacturer data }\end{array}$ \\
\hline & \multicolumn{4}{|c|}{ Shell and tube tank } \\
\hline III & $\begin{array}{l}\text { Wagner Solar } \\
\text { GMBH }\end{array}$ & $\begin{array}{l}\text { Shower Collector } \\
\text { ECOshower }\end{array}$ & $34.9-43.2$ & $\begin{array}{l}\text { Eff. depends on the } \\
\text { media flow, the lowest } \\
\text { value obtained at the } \\
\text { flow of } 601 / \mathrm{min}\end{array}$ \\
\hline & \multicolumn{4}{|c|}{ Horizontal heat exchanger } \\
\hline IV & Ecodrain TM & B1000 & 41.0 & $\begin{array}{l}\text { Obtained at the flow of } \\
9.51 / \mathrm{min}\end{array}$ \\
\hline
\end{tabular}

\section{Analysis and discussion}

The results of measurements which carried out over four years in two polish hospitals with over 600 beds were presented in [2]. This paper contains the wide studies of heat consumption for DHW preparation. These results were used to assess the possibility of saving energy to prepare DHW in hospitals as a result of implementation heat recovery system on water drain system from the hot water facilities (wash basins and showers). For all analysis the constant temperature of drain water was assumed, equals $35^{\circ} \mathrm{C}$, and the required temperature of DHW equals $60^{\circ} \mathrm{C}$. 


\subsection{Analysis for constant supply cold water temperature}

Fig. 2 presents the monthly energy consumption for the preparation of DHW. The four-year data for the hospital B, given in [2], were averaged. The cold water supply temperature was assumed to be equal $10^{\circ} \mathrm{C}$. The mean hourly hot-water demand $\left(V_{\mathrm{hwd}-\mathrm{m}}=5.17 \mathrm{l} / \mathrm{h} \cdot \mathrm{bed}\right)$ was determined assuming a constant cold water temperature during the year. It can be observed that the measured energy consumption during the year varies slightly (from 492 GJ to 602 GJ). However, the lowest energy consumption is in summer. After applying heat recovery from drain water and preheating of cold water, the lowest heat consumption for DHW was obtained for System I (see Table 2). The amount of heat recovered from drain water is almost constant during the year. The average monthly amount of recovered heat is 161 GJ with a standard deviation equal to $10 \mathrm{GJ}$. It is due to the assumption of a constant cold water temperature, which allows to obtain a constant temperature of preheated cold water (for System I equal to $24.6^{\circ} \mathrm{C}$ ).

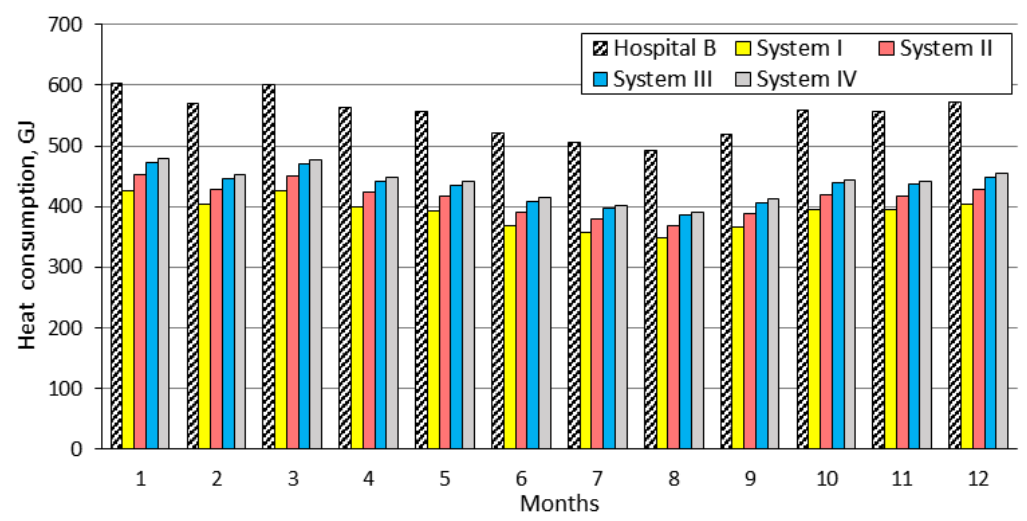

Fig. 2. Monthly heat consumption for DHW preparation in hospital B with four DWHR systems implementation (constant supply cold water temperature $10^{\circ} \mathrm{C}$ ).

\subsection{Analysis for variable supply cold water temperature}

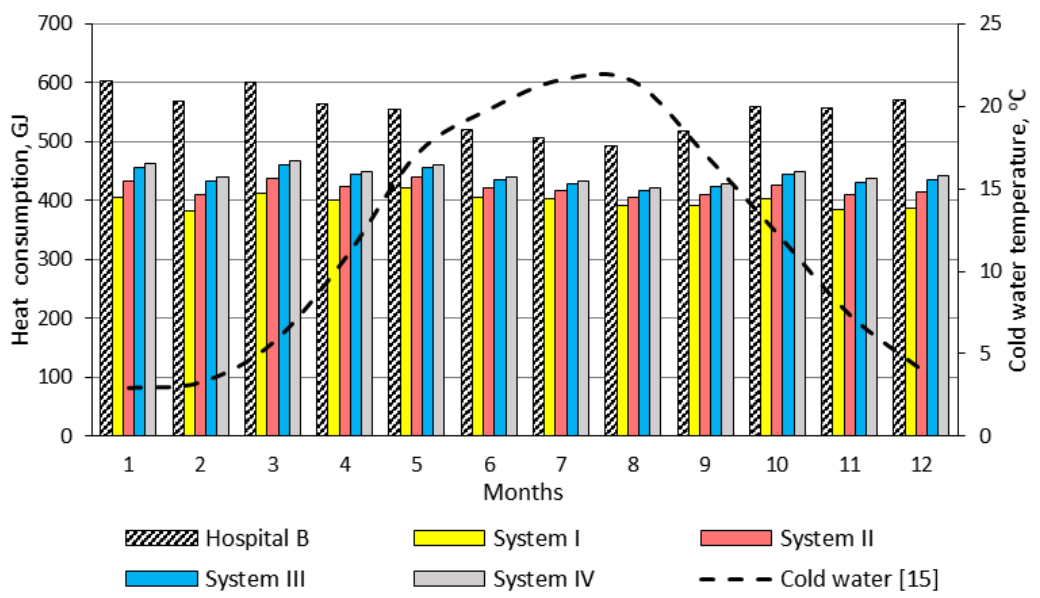

Fig. 3. Monthly heat consumption for DHW preparation in hospital B with four DWHR systems implementation (fluctuating temperature of the cold water supply throughout the year based on [15]). 
Fig. 3 shows the monthly energy consumption for the preparation of DHW taking into account the effect of the variable cold water temperature throughout the year. The cold water temperature was adopted based on [15]. According to the measurement data [2], a new $V_{\text {hwd-m }}$ value was determined. It is higher value than if a constant cold water temperature is assumed and is equal $5.49 \mathrm{l} / \mathrm{h} \cdot \mathrm{bed}$. Whereas for hospital A mean hourly hot-water demand increase from 4.63 to $4.88 \mathrm{l} / \mathrm{h} \cdot \mathrm{bed}$. The increase of $V_{\mathrm{hwd}-\mathrm{m}}$ results from the fact that the cold water temperature is higher than $10^{\circ} \mathrm{C}$ for most of the year. After applying the cold water temperature variation, in Fig. 3 a correlation between the lowest measured energy consumption for DHW and the highest cold water temperature can be observed. As in the first analysis, System I is the most effective. However, the monthly amount of heat recovered varies considerably (from 101 GJ in August to 198 GJ in January). It is due to the fact that as the temperature of the cold water supply increases, the temperature difference between the fluids in the heat recovery system decreases.

\subsection{Annual average heat consumption and heat recovered}

Fig. 4 presents the annual energy demand for the preparation of DHW per one hospital bed. The results for hospitals $\mathrm{A}$ and $\mathrm{B}$ were compared with the assumption of variable temperature of cold water. According to [2] average annual heat consumption for DHW per bed in hospital A and hospital B is equal $8.5 \mathrm{GJ} / \mathrm{y} \cdot$ bed and $9.6 \mathrm{GJ} / \mathrm{y} \cdot \mathrm{bed}$, respectively. The annual energy consumption for DHW in System I is $6.2 \mathrm{GJ} / \mathrm{y} \cdot$ bed and $6.9 \mathrm{GJ} / \mathrm{y} \cdot \mathrm{bed}$.

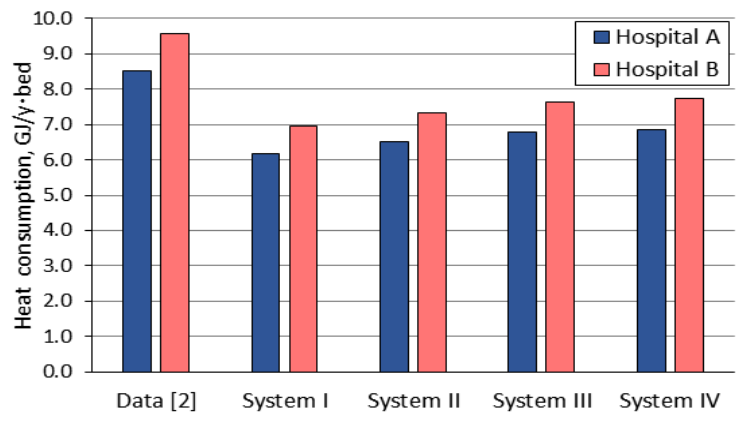

Fig. 4. Average annual heat consumption for domestic hot water per bed in hospital A and hospital B (fluctuating temperature of the cold water supply).

Table 3 summarizes the annual amount of recovered heat from drain water for hospitals A and B, expressed in $\mathrm{GJ} / \mathrm{y}$ and $\mathrm{GJ} / \mathrm{y} \cdot$ bed. The results for hospitals $\mathrm{A}$ and B were compared for both cases: with the assumption of constant and variable temperature of cold water. The influence of the adopted cold water temperature on the energy recovery efficiency is also presented in Table 3. It should be noted that the adoption of a variable cold water temperature causes a decrease in the amount of heat recovered from drain water. In hospital $\mathrm{B}$, for a constant cold water temperature, System I allows to reduce the annual energy demand for DHW by $29.2 \%(1932 \mathrm{GJ} / \mathrm{y})$, while taking into account the variable cold water temperature by $27.6 \%(1827 \mathrm{GJ} / \mathrm{y})$. 
Table 3. Average annual heat recovered from drain water in hospital A and hospital B.

\begin{tabular}{|c|c|c|c|c|c|c|c|c|c|}
\hline \multirow{3}{*}{$\begin{array}{c}\text { Heat } \\
\text { recovery } \\
\text { system }\end{array}$} & \multirow{3}{*}{$\begin{array}{l}\text { Heat } \\
\text { recovery } \\
\text { eff. } \varepsilon\end{array}$} & \multicolumn{8}{|c|}{ Heat recovered from drain water } \\
\hline & & \multicolumn{4}{|c|}{ Hospital A } & \multicolumn{4}{|c|}{ Hospital B } \\
\hline & & $\mathrm{GJ} / \mathrm{y}$ & $\mathrm{GJ} / \mathrm{y} \cdot \mathrm{bed}$ & $\mathrm{GJ} / \mathrm{y}$ & $\mathrm{GJ} / \mathrm{y} \cdot \mathrm{bed}$ & $\mathrm{GJ} / \mathrm{y}$ & $\mathrm{GJ} / \mathrm{y} \cdot \mathrm{bed}$ & $\mathrm{GJ} / \mathrm{y}$ & $\mathrm{GJ} / \mathrm{y} \cdot \mathrm{bed}$ \\
\hline- & $\%$ & \multicolumn{2}{|c|}{$\begin{array}{c}\text { Constant cold } \\
\text { water temp. } 10^{\circ} \mathrm{C}\end{array}$} & \multicolumn{2}{|c|}{$\begin{array}{l}\text { Variable cold } \\
\text { water temp. }\end{array}$} & \multicolumn{2}{|c|}{$\begin{array}{c}\text { Constant cold } \\
\text { water temp. } 10^{\circ} \mathrm{C}\end{array}$} & \multicolumn{2}{|c|}{$\begin{array}{l}\text { Variable cold } \\
\text { water temp. }\end{array}$} \\
\hline I & 58.4 & 1777 & 2.49 & 1678 & 2.35 & 1932 & 2.80 & 1827 & 2.65 \\
\hline II & 50.0 & 1521 & 2.13 & 1437 & 2.01 & 1654 & 2.40 & 1565 & 2.27 \\
\hline III & 43.2 & 1314 & 1.84 & 1241 & 1.74 & 1429 & 2.07 & 1352 & 1.96 \\
\hline IV & 41.0 & 1247 & 1.74 & 1178 & 1.65 & 1357 & 1.97 & 1283 & 1.86 \\
\hline
\end{tabular}

\section{Conclusion}

The possibility of reducing of energy to hot water preparation in hospitals as a result of implementation heat recovery system were assessed. Four types of heat exchangers was analysed with focusing on their heat recovery efficiency, type and construction. Vertical heat exchanger (e.g. ThermoDrain, Multivert) due to high efficiency administer possibility to recover more energy than in case of implementation of horizontal heat exchanger (e.g. B1000, ECOshower). The most amount of recovered energy (about 30\%) was gained due to implementation of shell and tube heat exchanger type GFX (System I). In case of constant supply cold water temperature, this device allows to recover $2.49 \mathrm{GJ} / \mathrm{y} \cdot \mathrm{bed}$ in hospital A, and $2.80 \mathrm{GJ} / \mathrm{y} \cdot$ bed in hospital B. In case of variable supply cold water temperature less recovered energy was obtained: $2.35 \mathrm{GJ} / \mathrm{y} \cdot \mathrm{bed}$ in hospital A, and $2.65 \mathrm{GJ} / \mathrm{y} \cdot$ bed in hospital B. By implementation of DWHR system, a significant heat consumption can be recovered and large fossil fuels can be reduced in healthcare buildings.

The work was partially financed by The Faculty of Environmental Energy, Wroclaw University of Science and Technology, Poland. No. 0401/0055/18.

\section{References}

1. Health and health care in 2016, Cent. Stat. Off. 91, 399-404 (2017)

2. J. Bujak, Energy Build. 42, 7, 1047-1055 (2010)

3. E. Fuentes, L. Arce, J. Salom, Renew. Sustain. Energy Rev. 81, 1530-1547 (2018)

4. M. A. Sayegh, P. Jadwiszczak, B. P. Axcell, E. Niemierka, K. Bryś, H. Jouhara, Energy Build. 166, 122-144 (2018)

5. J. García-Sanz-Calcedo, F. López-Rodriguez, T. Yusaf, Energies 10, 4 (2017)

6. S. Budzisz, B. Kłosek, Vademecum for designers of sanitary installations in hospitals

7. E. R. Recknagel, H. Sprenger, E. Schramek, Compedium of knowledge (2008)

8. Technical and design materials, Buderus, (2014)

9. S. Mańkowski, Designing Domestic Hot Water Installations (Arkady, 1981)

10. M. Arnell, E. Lundin, U. Jeppson, Sustainability analysis for wastewater heat recovery - Literature review (Lund Univerity, 2017)

11. A. Mazur, D. Słyś, J. Civ. Eng. 12, 2, 155-162 (2017)

12. A. R. Mazhar, S. Liu, A. Shukla, Energies 11, 2 (2018) 
13. A. Bertrand, A. Mastrucci, N. Schüler, R. Aggoune, F. Maréchal, Appl. Energy 186, 152-166 (2017)

14. J. Danielewicz, M. A. Sayegh, B. Śniechowska, M. Szulgowska-Zgrzywa, H. Jouhara, Energy 77, 82-87 (2014)

15. A. Chmielewska, E3S 44, 00017 (2018) 